\title{
Correction to: Determinants of habitat occupancy and spatial segregation of primates in the central Western Ghats, India
}

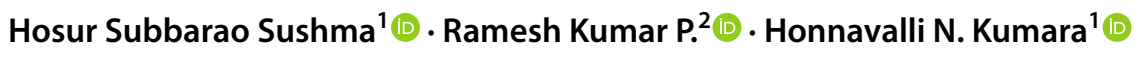

Published online: 11 February 2022

(c) The Author(s), under exclusive licence to Japan Monkey Centre 2022

\section{Correction to: Primates}

https://doi.org/10.1007/s10329-021-00966-y

In the original publication of the article, the second author's name was wrongly published. The correct name is given in this correction.

The original article has been corrected.

Publisher's Note Springer Nature remains neutral with regard to jurisdictional claims in published maps and institutional affiliations.

The original article can be found online at https://doi.org/10.1007/ s10329-021-00966-y.

Hosur Subbarao Sushma

sush61@gmail.com

Ramesh Kumar P.

rameshifos@gmail.com

Honnavalli N. Kumara

honnavallik@gmail.com

1 Salim Ali Centre for Ornithology and Natural History, Anaikatty (POST), Coimbatore 640118, Tamil Nadu, India

2 Karnataka Forest Department, Bannerghatta National Park, Bengaluru, Karnataka, India 